\title{
Five Challenges of Change Management
}

\author{
Evgeny A. Rudnev, \\ Academy of Public Administration, Senior Lecture, Ph.D. (Moscow, Russia)
}

Received: Apr. 19, 2020 Accepted: Oct. 26, 2020 Online published: Dec. 3, 2020

doi:10.5296/ijhrs.v10i4.18023ＵRL: https://doi.org/10.5296/ijhrs.v10i4.18023

\begin{abstract}
The five main challenges on the way of managing change in organizations at the present stage of development of science are differences in leaders, differences in management and changes mechanisms, markers of changes, the effectiveness of strategic actions, career of employees. A long and difficult path in theory and practice is the development and search for methods of social science. Human resource management and change management - openness of the question about the most effective mechanism of change in organizations.
\end{abstract}

Keywords: change management, organizations, challenges, strategic actions, leadership, existential vacuum, change markers, organizational memory, small business, large organization, change mechanism

\section{Introduction}

The theory of change has come a complicated and controversial path in the West. The foundations of social changes laid down in 1947 by K. Levin (Levin, 1947) entailed various studies after his death. Beginning with an experiment on changes the social scientists identified the phenomenon of resistance to changes and described the behavior of workers when changes were introduced (Coch, French,1948), wages and the negotiation process (Jacues,1950), the laws of social comparison of people (Festinger,1954), the value of national culture factor (Pascale,1978), understanding of involvement (Gardner,1977; Marcingtom, Wilkinson, Acckers, Goodman,1994) and the role of emotions (Ashforth, Humphrey,1995), team theory (Cohen, Letford,1994), attempts have been made to bring approaches closer together in studies of economics and anthropology (Buckley, Chapman,1996; Casson,1996).

The author of the article showed the relationship between the configuration of management teams and leadership motivation, directly laid the foundations for conducting research based on the biographical method, and an attempt is made to holistic study of the relationship between behavior in business organizations and national culture (Rudnev, 2013, 2018, 2019).

The results of these studies come to a greater understanding of organizations and processes, as well as the phenomena that arise in social systems, and the patterns of human behavior that 
explain their productivity and effectiveness. However, they do not bring a greater understanding of changes in organizations. All that we know today - the causes of project failures - lack of resources, tasks that are not part of the daily responsibilities, poor leadership, lack of control, poorly formulated and constantly changing goals, low level of responsibility.

This allows managers to look at their work and see mistakes, but does not bring them closer to understanding the more successful implementation of changes - identifying and justifying any universal ways to solve this problem. In addition, over the years of the development of social science - the theory of three steps - as the fundamental foundation - has undergone significant transformations, and has not brought closer to an understanding of the mechanisms of change, about which the founder of social change probably thought a lot (Cummings, Bridgman, Brown, 2016).

It would seem that the knowledge and empirical studies accumulated over more than fifty years create the basis for more productive changes in organizations. However, they create not so much understanding how to improve the organizational world as the new difficulties in the field of change management problems. It is possible that the difficulties identified and considered in this paper will allow us to approach the development of change mechanisms.

\section{Organizations Are Led by Leaders - They Are Different}

Today, not a single textbook containing sections on making changes contains information about the differences between the leaders of the organizations in which the changes are being made. In addition, scientific knowledge, as a rule, is presented in a generalized depersonalized form. And the most successful cases are summarized in separate publications. Meanwhile, when a consultant transgresses to introduce changes together with top management, he, as a rule, is not interested in who he is dealing with.

In science, to date, the leadership paths have been poorly studied, despite the fact that you can get acquainted with the biographies of the leaders of outstanding companies. However, at the level of generalizations, there are no conclusions. At the same time, at least three leadership strategies could be distinguished - the creation of a single product company, the movement from a specialist position to a general director position, and an entrepreneurial strategy. The last one is worth a closer look. It is most clearly manifested by the example of the life path of a Russian businessman - Oleg Tinkov. He began his career in business with the production of ravioli. The next business was the production of beer. The third business is a bank. In this case, the businessman, although he forms a brand under his own name, does not create a unique product, but only enters the existing niche with a similar (confusing product - auth.) And enters into competition with other entrepreneurs and companies. Unlike the first strategy, where the leader enters with a unique - new product to the market - like Steve Jobs and Apple, which changed and transformed over time. The second strategy differs from the first and third in that the leader is hired to manage the existing organization and for the developed product, demonstrating the ability or ability to take a leadership position. Accordingly, the motivation for supporting change may be different. In one case, market promotion, in the other - greater disclosure of the employees' potential for new developments, in the third - the formation of a new management team. As a rule, the literature does not 
describe tasks and ways to solve them, although back in 1960 years, the lack of research into the texture of organizations for making changes was emphasized (Emery, Trist, 1965). It is worthwhile to dwell on the "Oleg Tinkov syndrome" in more detail, since this type of leadership will most likely be distributed in the 21 st century, more often than other types of leadership strategies - like a coronavirus. The "entrepreneurial coronavirus" will be the result of crises that periodically occur in the new time, which will release labor resources on the market and lead people to search for options to fill the "existential vacuum" as a sign of the post-crisis period - to lead people to search for new meanings and unite to overcome it . That is, an increasing number of people will seek to find employment options together with other people. To do this, they will need cooperation, creativity and enterprise. In this case, we can say that the consultation process should be based on the consideration of each individual case - each organization - as unique.

\section{Differences in Organizational Management Mechanisms and Change Mechanisms}

It is known that business differs in the number of employees and the company's turnover in monetary terms, on the basis of which it is classified as small, medium and large. It is shown that small businesses rarely resort to training services, unlike large ones. In addition, the effectiveness of the impact of training on the performance of small businesses has not been proven (De Kok, 2003). In this connection, questions arise - whether the consultation process and the mechanisms of changes in large and small organizations differ.

It is not entirely clear what distinguishes medium-sized businesses, as they are more often associated with small than with large businesses. It's not clear that this is a business that has gone beyond small, but has not reached large momentum, a niche in the economy — where the needs of customers do not allow them to go beyond the middle level, but at the same time they allow them to stably present and develop in the market, organizations that have the potential, but they have not reached the peak of development, stable niches in the economy in which there is a need, providing the narrow needs of customers or representing one or more types of services. In this regard, organizations can differ both in terms of management mechanisms and the organization of social systems - for example, service, interaction with the client. It is clear that a large organization contains more levels of management, has a more developed hierarchy and more formalized procedures, in comparison with a small organization, which does not mean that they are not in smaller organizations. Nevertheless, it is obvious that a different organization of organizations may entail various mechanisms of change, which are not yet fully understood at present. In addition, the problems that large and medium-sized businesses have are different. To date, they are not classified. There are special cases in the literature describing the work of consultants with organizations, which is of interest and allows you to get acquainted with experience, but does not allow you to apply the solution to other organizations.

\section{Identify Organization Problem Areas and Change Markers}

Among the success factors of changes is called freezing (in the terminology of K. Levin), which may consist in rewriting job descriptions, fixing new roles, otherwise, no changes occur. One of the difficulties lies in the formation of markers of changes - that is, determining 
a list of actions or behavior by which to judge the changes that have taken place. It can be supported by the learning process and the involvement of staff in the change process. For example, starting with a joint definition of the difficulties of working with clients of sales consultants and ways to overcome them - as new standards of behavior in the workplace, which could increase the level of satisfaction with the company's service. This requires fixing the points or problem areas that exist in the organization. However, in this case, the causes of the problem area may be ambiguous. On the one hand, this may be the behavior of employees, and on the other, motivation and behavior of the clients themselves, which may not lend itself to universal classification, in order to find standard answers or reactions to all cases in service. The key aspect is the question - the level of criticality of the process or procedure adopted by the organization to determine it as subject to change. It seems that the level of criticality can not always be expressed in monetary terms, which requires a sense of managers and leaders. It is known that changes begin with the dissatisfaction of the leader. Also known is the classification of changes in organizations proposed by E. Schein (organizational culture, strategy, structure, procedures, employee qualifications) (Schein, 2013). Each subsequent level entails changes at the previous level. To change the structure - that is, to redistribute power - it is necessary to change the procedures and qualifications, in order to change the organizational culture - it is necessary to change the strategy, structure, procedure, qualifications). Each subsequent level requires more energy and strength for change. It is difficult to establish transition points between levels, since, as a rule, changes cover several departments at the same time and the organization as a whole. However, in addition to fixing roles, symbolic management can be actively used - new language and symbols that arise in the process of interaction within units - similar to the language used by scuba divers in a threat situation and astronauts in conditions of limiting verbal communication, including sign language indicating actions or threats.

\section{The Degree of Effectiveness of Strategic Actions During Changes}

One of the prime examples of change is McDonald's. In 2010, the company lost its leadership in the fast food segment. A few years ago, the company attempted to change at every point of sale. In particular, the functions of placing and issuing an order were divided. The desktop of employees directly communicating with customers is divided into two zones - cash desk and order issuance. Workplaces of employees are equipped with a screen with a list of orders. In addition, instead of an employee receiving orders in the hall, automated points for self-ordering appeared. The main client of McDonald's is a student. Technical changes and the development of information technology pushed the company to introduce information technology both in the technological process and in the process of working with clients, since the main contingent of the company's employees is also young people. For McDonald's, technical changes and the introduction of information technology were followed by trade companies. Today we can see how on the screen when ordering food the client can see - its content (name, weight, cost). This information is recorded on the card, from which the client goes to the cashier. Some retail organizations have acted even more radically - installing machines and payment exclusively by credit card. However, the introduction of these innovations did not lead to the return of McDonald's to a leading position in the market. One 
of the difficulties in introducing changes is that the introduction of information technology and the division of labor tasks do not lead to the monetization of enterprises. In this case, the changes become formal and reflect only the spirit of the times. Today there are no tools to assess the effectiveness of actions taken for the future, even if they are implemented quite successfully.

\section{Organizational Memory and the Connection of Changes With the Career of Employees}

It is known that the key obstacle to change is the organizational culture and organizational memory - the accepted order and work experience. The crisis of 2020 caused by the pandemic showed that not all organizations (from different sectors of the economy) were ready to switch to electronic - remote format for working with a client, which entailed financial losses or even the closure of the business. The management of any organization conducting changes is interested in their implementation. However, the connection between the changes and the career of people in the organization is often not clear.

In the case when individual employees are most successful, they can move up the career ladder, which leads to a breakdown in the existing relationships in the organization redistribution of management attention, additional resources, and demotivation of employees who are less successful in making changes. In addition, Russian business organizations still do not recognize the connection between the training process, which can be aimed at supporting changes, and the effectiveness of the organization. Often, assessment of training is carried out on the career advancement of employees. However, this is the exception rather than the rule in organizations.

In addition, due to the hierarchy of large organizations, changing organizational memory takes time - repeating the procedures and the order of the work, which requires the diversion of energy and the forces of the changes, as a result of which the change team may lose.

\section{Conclusion}

The accumulated knowledge in the field of leadership and management does not reduce the degree of clarity of mechanisms for changes in organizations. The search for optimal change management paths revealed five key difficulties that are becoming in the way of finding optimal change mechanisms. They are related to the degree of effectiveness of strategic actions in case of changes and the lack of tools for evaluating them, differences in leadership achievement strategies and leaders' life paths, identification of change markers, organizational memory and career of employees, differences in management mechanisms and social systems of large, medium and small organizations.

The connection between the implementation of information technology in the production process and the monetization of organizations is not obvious. At the same time, in the $21 \mathrm{st}$ century, an "existential vacuum" will push people closer and closer, pushing them to unite, which will require cooperation, creativity and enterprise. In the process of change will be the problem of identifying markers to assess the success of their implementation. What can be 
used symbolic management. Implementation of changes is accompanied by training. However, the relationship with its effectiveness and career is not recognized in organizations, and employee promotion is the exception rather than the rule. Organizations are distinguished by management mechanisms, and business problems are not classified, despite the fact that the precedents for advising individual companies and organizations are described. Understanding these difficulties allows us to formulate a field of problems for finding the most effective mechanisms of change, to determine what is included and not included in the field of attention of theoreticians and consultants today and thus outline the future both for the development of science and empirical ways of solving the problem of change management.

\section{References}

Ashforth, B. E., \& Humphrey, R. H. (1995). Emotion in the workplace: A reappraisal. Human relations, 48(2), 97-125. https://doi.org/10.1177/001872679504800201

Buckley, P. J., \& Chapman, M. (1998). Economics and social anthropology: Reconciling differences. In International Business (pp. 24-56). Palgrave Macmillan, London. https://doi.org/10.1007/978-1-349-26416-2_2

Casson, M. (1996). Economics and Anthropology-reluctant partners. Human Relations, 49(9), 1151-1180. https://doi.org/10.1177/001872679604900902

Cummings, S., Bridgman, T., \& Brown, K. G. (2016). Unfreezing change as three steps: Rethinking Kurt Lewin's legacy for change management. Human Relations, 69(1), 33-60. https://doi.org/10.1177/0018726715577707

Coch, L., \& French Jr, J. R. (1948). Overcoming resistance to change. Human relations, 1(4), 512-532. https://doi.org/10.1177/001872674800100408

Cohen, S. G., \& Ledford Jr, G. E. (1994). The effectiveness of self-managing teams: A quasi-experiment. Human relations, 13-43. https://doi.org/10.1177/001872679404700102

de Kok, J. (2003). Human resource management within small and medium-sized enterprises (No. 313). Rozenberg Publishers.

Emery, F. E., \& Trist, E. L. (1965). The causal texture of organizational environments. Human relations, 18(1), 21-32. https://doi.org/10.1177/001872676501800103

Festinger, L. (1954). A theory of social comparison processes. Human relations, 7(2), 117-140. https://doi.org/10.1177/001872675400700202

Gardner, G. (1977). Workers' participation: A critical evaluation of Coch and French. Human Relations, 30(12), 1071-1078. https://doi.org/10.1177/001872677703001201

Jacques, E. (1950). Studies in the social development of an industrial community (the Glacier project). I. Collaborative group methods in a wage negotiation situation. Part One: Case study. Human Relations. https://doi.org/10.1177/001872675000300301 


\section{Macrothink}

International Journal of Human Resource Studies

ISSN 2162-3058 2020, Vol. 10, No. 4

Lewin, K. (1947). Frontiers in group dynamics: concept, method and reality in social science; social equilibria and social change. Human Relations. https://doi.org/10.1177/001872674700100103

Marchington, M., Wilkinson, A., Ackers, P., \& Goodman, J. (1994). Understanding the meaning of participation: Views from the workplace. Human relations, 47(8), 867-894. https://doi.org/10.1177/001872679404700801

Pascale, R. T. (1978). Personnel practices and employee attitudes: A study of Japaneseand American-managed firms in the United States. Human Relations, 31(7), 597-615. https://doi.org/10.1177/001872677803100703

Rudnev, E. (2018). Human as a subject of biographical research: history and methodology. Fundamental and applied researches in practice of leading scientific schools, 25(1), 114-119.

Rudnev, E. (2019). Russians in Business: An Analytical Study of Culture, Governance and Behavior. European Journal of Behavioral Sciences, 2(2), 9-16. https://doi.org/10.33422/ejbs.v2i2.147

Rudnev, E. (2013). Understanding Leadership: Biographic, Gender and Social Aspects. $\begin{array}{llllll}\text { Mediterranean Journal of } & \text { Social } & \text { Sciences, } & 4(9), & \end{array}$ https://doi.org/10.5901/mjss.2013.v4n9p714

Schein, E. H. (2010). Organizational culture and leadership (Vol. 2). John Wiley \& Sons.

\section{Copyright Disclaimer}

Copyright for this article is retained by the author(s), with first publication rights granted to the journal.

This is an open-access article distributed under the terms and conditions of the Creative Commons Attribution license (http://creativecommons.org/licenses/by/4.0/). 